\title{
Clinical Outcomes in Diabetic Patients with Stable Coronary Artery Disease Treated with Second- Generation Drug Eluting Stents (Short and Mid-Term Follow Up)
}

\author{
Ehab Abdelwahab Hamdy, Mohamed Naseem Hussien, Ayman Ahmed El Sheikh, \\ Mohamed Abdel Moatty Emam* \\ Department of Cardiovascular Medicine, Faculty of Medicine, Tanta University \\ * Corresponding author: Mohamed Abdel Moatty Emam, Mobile: (+20) 01144556670, E-mail: \\ dr.emamclinic@gmail.com
}

\begin{abstract}
Buckhound: The increased prevalence of type 2 diabetes mellitus (DM) is an important public health problem. The number of patients with DM worldwide is estimated to rise to 366 million by the year 2030. In general, individuals with DM have more severe and diffuse atherosclerotic disease, which accounts for the significantly higher incidence of cardiovascular events in their native coronary, cerebrovascular, and peripheral arteries.

Objective: The aim of this study was to assess the short and mid-term clinical outcomes in type 2 diabetic patients with stable coronary artery disease treated with 2nd generation drug eluting stents.

Patients and Methods: This prospective observational study included a total of 100 type 2 DM-CAD patients, attending at Department of Cardiology, Tanta University Hospitals. This study was conducted between January 2018 till January 2019. Assessment of the mid and short-term clinical outcomes in patients was done.

Results: Non-significant difference as regards age, sex and family history $(p>0.05)$ was found. Non-significant difference as regards height, weight, BMI, HTN and smoking $(p>0.05)$ was found. Significant increase in inverted T wave in Major Adverse Cardiovascular Events $\quad$ (MACE) group; compared to normal group; with significant statistical difference $(\mathrm{p}=0.015)$. Non-significant difference as regards creatinine, ST elevation, ST depression, pathological Q, LBBB and RBBB ( $p>0.05$ ) were found. Highly significant decrease in EF in MACE group; compared to normal group; with highly significant statistical difference $(\mathrm{p}<0.01)$ were found.

Conclusion: Diabetes mellitus is a condition in which the use of 2nd generation zotarolimus-eluting stents is preferable, in order to reduce the incidence of MACE adverse events.
\end{abstract}

Keywords: Diabetic, Coronary artery disease treated, Second- Generation drug eluting stents.

\section{INTRODUCTION}

The increased prevalence of type 2 diabetes mellitus (DM) is an important public health problem. The number of patients with DM worldwide is estimated to rise to 366 million by the year 2030. In general, individuals with DM have more severe and diffuse atherosclerotic disease, which accounts for the significantly higher incidence of cardiovascular events in their native coronary, cerebrovascular, and peripheral arteries. In addition to aggravated atherosclerosis in native coronary arteries, DM is a well-known independent risk factor for worse outcomes after coronary stent implantation, such as angiographic restenosis, target lesion revascularization (TLR), late and very late stent thrombosis, and even all-cause death ${ }^{(\mathbf{1}, \mathbf{2})}$.

Second-generation durable polymer drugeluting stents (DES), including a durable polymer zotarolimus eluting stent, have demonstrated good efficacy in the treatment of coronary artery disease in diabetic patients $(3,4)$. However, persistent inflammatory response to durable polymer coatings of DES is recognized as a leading cause of delayed arterial healing and one of the key factors underlying late stent failure in patients who undergo DES implantation ${ }^{(5,6)}$. Indeed, this issue is of particular relevance in the setting of diabetic patients with high atherothrombotic risk ${ }^{(7)}$.

The aim of this study was to assess the short and mid-term clinical outcomes in diabetic patients with stable coronary artery disease treated with 2nd generation drug eluting stents.

\section{PATIENTS AND METHODS}

This prospective observational study included a total of 100 DM-CAD patients (64 male and 36 female with average age 57.9 years), attending at Department Of Cardiology, Tanta University Hospitals. This study was conducted between January 2018 till January 2019.

\section{Ethical consideration and Written informed consent:}

An approval of the study was obtained from Tanta University academic and ethical committee. Every patient signed an informed written consent for acceptance of the operation.

Inclusion criteria: Diabetic patients with type 2 DM, with chronic stable angina treated with 2nd generation DES. 


\section{Exclusion criteria:}

1. Age $<18$ years.

2. Patient with atrial fibrillation $(\mathrm{AF})$.

3. Patient with valvular heart disease.

4. Patient with heart failure (HF).

5. Patient with previous CVS.

6. Non-diabetic patients.

7. Unstable angina.

8. Acute myocardial infarction.

\section{All study population underwent the following work up:}

Full medical history, general and cardiac examinations: Including the personal history, risk factors as hypertension, diabetes mellitus, obesity, drug intake, smoking and comorbid diseases including renal, hepatic diseases or collagen disorders etc.

Full general clinical examination was conducted including; assessment of general appearance, body weight $(\mathrm{Kg})$, height measurement (meters), and body mass index (BMI) calculation, along with meticulous cardiac examination.

\section{Investigational studies}

Signs of heart failure was looked for and recorded which include pulmonary rales, pleural effusion, elevated jugular venous pressure (JVP) $>6 \mathrm{~cm}$, lower limb edema, hepatomegaly, ascites, third heart sound, murmur and cold extremities.

Electrocardiogram: Standard 12-lead electrocardiography was done on admission.

\section{Transthoracic Echocardiography}

Resting standard transthoracic Echocardiography (TTE) was done to all patients. Machine: GE vived $5 \mathrm{~S}$, vived 3, vived 7.

\section{Follow up:}

Data were obtained in outpatient clinic or by mobile phone contact, regarding clinical end-points according to MACE (major adverse cardiac events) criteria including:

1. Death.

2. Myocardial infarction (STEMI and NSTEMI).

3. Cerebrovascular stroke.

4. In-stent restenosis.

5. Stent thrombosis.

6. Target lesion revascularization.
Primary outcome: Mortality rate. Secondary outcomes:

1. Myocardial infarction (STEMI and NSTEMI).

2. Cerebrovascular stroke.

3. In-stent restenosis.

4. Stent thrombosis.

5. Target lesion revascularization.

The risks to participants and measures used to minimize the risk: The following data was collected from all patients e.g. heart failure evidenced by symptoms and/ or signs of heart failure (at rest or during exercise), and objective evidence (preferably by echocardiography) of cardiac dysfunction (systolic and/or diastolic) (at rest), atrial fibrillation evidenced by ECG and smoking or ex-smoking).

- Participants privacy and confidentiality of the data were provided.

\section{Statistical analysis:}

Recorded data were analyzed using the statistical package for social sciences, version 20.0 (SPSS Inc., Chicago, Illinois, USA). Quantitative data were expressed as mean \pm standard deviation (SD). Qualitative data were expressed as frequency and percentage.

\section{The following tests were done:}

- Independent-samples t-test of significance was used when comparing between two means.

- Chi-square $\left(\mathrm{x}^{2}\right)$ test of significance was used in order to compare proportions between two qualitative parameters.

- The confidence interval was set to $95 \%$ and the margin of error accepted was set to $5 \%$. The pvalue was considered significant as the following:

- Probability (P-value)

- P-value <0.05 was considered significant.

- P-value <0.001 was considered as highly significant.

- P-value >0.05 was considered insignificant.

\section{RESULTS \\ Descriptive data:}

The demographic and clinical variables in 100 DM-CAD patients who were included in the study are shown in the following tables \& figures: 
Baseline data:

Table (1): Baseline clinical data among $100 \mathrm{DM}-$ CAD patients:

\begin{tabular}{|c|c|c|}
\hline \multicolumn{2}{|l|}{ Variables } & Frequency (\%) \\
\hline \multicolumn{2}{|l|}{ Age (years) } & $57.96 \pm 8.32 *$ \\
\hline \multicolumn{2}{|l|}{ Height $(\mathrm{cm})$} & $168.4 \pm 9.1$ \\
\hline \multicolumn{2}{|l|}{ Weight $(\mathrm{kg})$} & $86.5 \pm 10.1$ \\
\hline \multicolumn{2}{|l|}{ BMI $\left(\mathrm{kg} / \mathrm{m}^{2}\right)$} & $30.7 \pm 4.6$ \\
\hline \multicolumn{2}{|c|}{ Family history } & $36(36 \%)$ \\
\hline \multicolumn{2}{|c|}{ HTN } & $64(64 \%)$ \\
\hline \multicolumn{2}{|l|}{ Smoking } & $58(58 \%)$ \\
\hline Gender & $\begin{array}{l}\text { Female } \\
\text { Male }\end{array}$ & $\begin{array}{l}36(36 \%) \\
64(64 \%)\end{array}$ \\
\hline \multirow[b]{2}{*}{ Perior } & PCI & $6(6 \%)$ \\
\hline & $\overline{\mathrm{CABG}}$ & $10(10 \%)$ \\
\hline Interventions & $\begin{array}{l}\text { GIIb/IIIa } \\
\text { inhibitors }\end{array}$ & $10(10 \%)$ \\
\hline
\end{tabular}

* Mean \pm SD. BMI: body mass index, HTN: hypertension.

Table (1) shows that; the mean age of all patients was $(57.96 \pm 8.32)$ years. Regarding gender of the patients, the majority $(64 \%)$ were males; while (36\%) were females, with $(36 \%)$ of patients had positive family history. The mean BMI of all patients was $(30.7 \pm 4.6)\left(\mathbf{k g} / \mathbf{m}^{2}\right)$. Regarding risk factors and co-morbidities, $(58 \%)$ of patients were smokers, and (64\%) were hypertensive.

Table (1) shows also that; (6\%) of patients had Baseline PCI, (10\%) had Baseline CABG, and (10\%) used GIIb/IIIa inhibitors.

Table (2): Baseline laboratory, ECG and echocardiographic data among 100 DM-CAD patients:

\begin{tabular}{|c|c|c|c|}
\hline \multicolumn{4}{|c|}{ Frequency $(\%)$} \\
\hline Lab & \multicolumn{2}{|c|}{ Creatinine $(\mathrm{mg} / \mathrm{dl})$} & $1.06 \pm 0.24$ \\
\hline \multirow{8}{*}{ ECG } & \multicolumn{2}{|c|}{ ECG abnormality } & $90(90 \%)$ \\
\hline & \multirow{2}{*}{\multicolumn{2}{|c|}{$\begin{array}{l}\text { Inverted } T \text { wave } \\
\text { ST elevation }\end{array}$}} & $64(64 \%)$ \\
\hline & & & $0(0 \%)$ \\
\hline & \multicolumn{2}{|c|}{ ST depression } & $10(10 \%)$ \\
\hline & \multicolumn{2}{|c|}{ Pathological Q } & $6(6 \%)$ \\
\hline & \multicolumn{2}{|c|}{ LBBB } & $22(22 \%)$ \\
\hline & \multicolumn{2}{|l|}{ RBBB } & $0(0 \%)$ \\
\hline & \multicolumn{2}{|l|}{$\mathbf{A F}$} & $0(0 \%)$ \\
\hline \multirow[t]{7}{*}{ Echo } & \multicolumn{2}{|l|}{$\mathbf{E F}(\%)$} & $60.5 \pm 10.7$ \\
\hline & \multicolumn{2}{|l|}{ RWMA } & $72(72 \%)$ \\
\hline & \multicolumn{2}{|l|}{ LVH } & $54(54 \%)$ \\
\hline & $\begin{array}{l}\text { Grade of } \\
\text { DD }\end{array}$ & $\begin{array}{l}\text { Grade I } \\
\text { Grade II }\end{array}$ & $\begin{array}{l}84(84 \%) \\
16(16 \%)\end{array}$ \\
\hline & \multirow{3}{*}{$\begin{array}{l}\text { Valve } \\
\text { abnormali } \\
\text { ty }\end{array}$} & Normal & $83(83 \%)$ \\
\hline & & Mild MR & $9(9 \%)$ \\
\hline & & Mild TR & $8(8 \%)$ \\
\hline
\end{tabular}

BBB: bundle branch block (L: left, R: right). AF: atrial fibrillation. EF: ejection fraction. RWMA: regional wall motion abnormality. DD: diastolic dysfunction. LVH: left ventricular hypertrophy. MR: mitral regurge. TR: tricuspid regurge.

This table shows that; the mean creatinine of all patients was $(1.06 \pm 0.24) \mathrm{mg} / \mathrm{dl}$. Regarding ECG abnormalities, (90\%) of patients had abnormal ECG findings, with (64\%) had inverted T wave, (10\%) had ST depression, (6\%) had pathological Q, and (22\%) had LBBB. This table shows that; the mean $\mathrm{EF}$ of all patients was $(60.5 \pm \%)$; with $(72 \%)$ of patients had RWMA, (54\%) of patients had LVH.

Regarding grades of DD, (84\%) of patients had grade I DD, and (16\%) had grade II DD. Regarding valve abnormalities, (9\%) of patients had mild MR, and $(8 \%)$ had mild TR.

Outcome (short and mid-term follow up) data: Table (3): Outcome data among 100 DM-CAD patients:

\begin{tabular}{|l|l|l|}
\hline \multicolumn{2}{|l|}{ Variables } & Frequency (\%) \\
\hline Prevalence of MACE \# & $18(18 \%)$ \\
\hline 1ry outcome & $\begin{array}{l}\text { Mortality } \\
\text { rate }\end{array}$ & $2(2 \%)$ \\
\hline 2ry outcomes & $\begin{array}{l}\text { STEMI } \\
\text { NSTEMI }\end{array}$ & $0(0 \%)$ \\
& $\begin{array}{l}6(6 \%) \\
\text { CVS }\end{array}$ & $0(0 \%)$ \\
& $\begin{array}{l}\text { IRS } \\
\text { Stent } \\
\text { thrombosis }\end{array}$ & $12(12 \%)$ \\
& Target & $6(6 \%)$ \\
& $\begin{array}{l}\text { revasculari } \\
\text { zation } \\
\text { lesion }\end{array}$ & \\
\hline
\end{tabular}

\# each patient suffered more than one MACE event. MACE: Major acute cardiovascular events. STEMI: ST elevation myocardial infarction. CVS: Cerebrovascular stroke. IRS: in stent restenosis.

This table shows that; the prevalence of MACE events was (18\%), with mortality rate of (2\%), and (6\%) had NSTEMI, (12\%) had IRS, (2\%) had stent thrombosis, and (6\%) had target lesion revascularization. 
(4): Comparison between the 2 groups as regards baseline laboratory and ECG data using Mann-Whitney's U and Chi square tests:

\begin{tabular}{|c|c|c|c|c|}
\hline \multirow{2}{*}{\multicolumn{2}{|c|}{ Variable }} & $\begin{array}{l}\text { MACE group } \\
\text { (18) }\end{array}$ & $\begin{array}{c}\text { Normal group } \\
(82)\end{array}$ & $\begin{array}{c}\text { Mann- } \\
\text { Whitney's U test }\end{array}$ \\
\hline & & Median (IQR) & Median (IQR) & $\mathrm{P}$ value \\
\hline \multicolumn{2}{|l|}{ Creatinine (mg/dl) } & $1(1-1.3)$ & $1(0.8-1.2)$ & $=0.053$ \\
\hline \multicolumn{2}{|l|}{ Variable } & $\begin{array}{c}\text { MACE group } \\
\text { (18) }\end{array}$ & $\begin{array}{c}\text { Normal group } \\
(82)\end{array}$ & $\frac{\text { Chi square test }}{\text { P value }}$ \\
\hline \begin{tabular}{|l|} 
Inverted T wave \\
\end{tabular} & $+\mathrm{ve}$ & $16(88.9 \%)$ & $48(58.5 \%)$ & $=0.015^{*}$ \\
\hline ST elevation & $+\mathrm{ve}$ & $0(0 \%)$ & $0(0 \%)$ & $=1.000$ \\
\hline ST depression & $+\mathrm{ve}$ & $4(22.2 \%)$ & $6(7.3 \%)$ & $=0.057$ \\
\hline Pathological Q & $+\mathrm{ve}$ & $0(0 \%)$ & $6(7.3 \%)$ & $=0.238$ \\
\hline LBBB & $+\mathrm{ve}$ & $2(11.1 \%)$ & $20(24.4 \%)$ & $=0.220$ \\
\hline RBBB & $+\mathrm{ve}$ & $0(0 \%)$ & $0(0 \%)$ & $=1.000$ \\
\hline
\end{tabular}

* Percentage of Column Total.

Comparative study between the 2 groups revealed; significant increase in inverted T wave in MACE group; compared to normal group; with significant statistical difference $(\mathrm{p}=0.015)$.

Comparative study between the 2 groups revealed non- significant difference as regards creatinine, ST elevation, ST depression, pathological Q, LBBB and RBBB ( $\mathrm{p}>0.05)$.

Table (5): Comparison between the 2 groups as regards baseline echocardiographic data using MannWhitney's U and Chi square tests:

\begin{tabular}{|c|c|c|c|c|}
\hline \multirow{2}{*}{\multicolumn{2}{|c|}{ Variable }} & MACE group (18) & Normal group (82) & $\begin{array}{l}\text { Mann- Whitney's } \\
\text { U test }\end{array}$ \\
\hline & & Median (IQR) & Median (IQR) & P value \\
\hline \multicolumn{2}{|l|}{ EF $(\%)$} & $50(40-57)$ & $63(55-70)$ & $=0.000008^{* *}$ \\
\hline \multirow{2}{*}{\multicolumn{2}{|c|}{ Variable }} & \multirow[t]{2}{*}{ MACE group (18) } & \multirow{2}{*}{$\begin{array}{l}\text { Normal group } \\
(82)\end{array}$} & Chi square test \\
\hline & & & & P value \\
\hline RWMA & $+\mathrm{ve}$ & $16(88.9 \%)$ & $56(68.3 \%)$ & $=0.079$ \\
\hline LVH & $+\mathrm{ve}$ & $6(33.3 \%)$ & $48(58.5 \%)$ & $=0.053$ \\
\hline Grade of DD & $\begin{array}{l}\text { Grade I } \\
\text { Grade II }\end{array}$ & $\begin{array}{l}14(77.8 \%) \\
4(22.2 \%)\end{array}$ & $\begin{array}{l}70(85.4 \%) \\
12(14.6 \%)\end{array}$ & $=0.428$ \\
\hline
\end{tabular}

* Percentage of Column Total.

Comparative study between the 2 groups revealed; highly significant decrease in EF in MACE group; compared to normal group; with highly significant statistical difference $(\mathrm{p}<0.01)$.

Comparative study between the 2 groups revealed non- significant difference as regards RWMA, LVH, and grades of DD $(\mathrm{p}>0.05)$.

Table (6): Comparison between the 2 groups as regards coronary artery data using Mann-Whitney's U and Chi square tests:

\begin{tabular}{|c|c|c|c|c|}
\hline \multirow{2}{*}{\multicolumn{2}{|c|}{ Variable }} & $\begin{array}{l}\text { MACE group } \\
\text { (18) }\end{array}$ & $\begin{array}{l}\text { Normal group } \\
(82)\end{array}$ & $\begin{array}{l}\text { Mann- Whitney's } \\
\text { U test }\end{array}$ \\
\hline & & Median (IQR) & Median (IQR) & $P$ value \\
\hline \multicolumn{2}{|c|}{ Number of affected coronaries } & $1(1-1)$ & $2(1-2)$ & $=0.0048^{*} *$ \\
\hline \multirow{2}{*}{\multicolumn{2}{|c|}{ Variable }} & MACE group & Normal group & Chi square test \\
\hline & & (18) & $(82)$ & P value \\
\hline \multirow{4}{*}{$\begin{array}{l}\text { Affected } \\
\text { artery }\end{array}$} & LM & $0(0 \%)$ & $0(0 \%)$ & $=1.000$ \\
\hline & LAD & $10(55.6 \%)$ & $58(70.7 \%)$ & $=0.213$ \\
\hline & LCX & $6(33.3 \%)$ & $28(34.1 \%)$ & $=0.947$ \\
\hline & RCA & $9(50 \%)$ & $52(63.4 \%)$ & $=0.293$ \\
\hline \multicolumn{2}{|c|}{ Syntax score } & $23-28$ & Less than 22 & $=0.039$ \\
\hline
\end{tabular}

Comparative study between the 2 groups revealed; highly significant decrease in number of affected coronaries, in MACE group; compared to normal group; with highly significant statistical difference $(\mathrm{p}=$ 0.0048). Comparative study between the 2 groups revealed; highly significant increase in syntax score, in MACE group; compared to normal group; with highly significant statistical difference $(p=0.0039)$.

Comparative study between the 2 groups revealed non- significant difference as regards LM, LAD, and LCX affection $(\mathrm{p}>0.05)$. 
Interventional data:

Table (7): Comparison between the 2 groups as regards interventional data using Mann-Whitney's U and Chi square tests:

\begin{tabular}{|c|c|c|c|c|}
\hline \multirow{2}{*}{\multicolumn{2}{|c|}{ Variable }} & $\begin{array}{l}\text { MACE group } \\
\text { (18) }\end{array}$ & $\begin{array}{l}\text { Normal group } \\
\text { (82) }\end{array}$ & $\begin{array}{l}\text { Mann- } \\
\text { Whitney's U } \\
\text { test }\end{array}$ \\
\hline & & Median (IQR) & Median (IQR) & $P$ value \\
\hline \multirow{2}{*}{$\begin{array}{l}\text { Current } \\
\text { interventions }\end{array}$} & $\begin{array}{l}\text { Number of treated } \\
\text { coronaries }\end{array}$ & $1(1-1)$ & $1(1-2)$ & $=0.459$ \\
\hline & Total stented length (mm) & $38(36-50)$ & $38(33-63)$ & $=0.814$ \\
\hline \multirow{2}{*}{\multicolumn{2}{|c|}{ Variable }} & $\begin{array}{l}\text { MACE group } \\
\text { (18) }\end{array}$ & $\begin{array}{l}\text { Normal group } \\
\text { (82) }\end{array}$ & $\begin{array}{l}\text { Chi square } \\
\text { test }\end{array}$ \\
\hline & & & & P value \\
\hline \multirow{3}{*}{$\begin{array}{l}\text { Baseline } \\
\text { interventions }\end{array}$} & PCI & $2(11.1 \%)$ & $4(4.9 \%)$ & $=0.315$ \\
\hline & CABG & $4(22.2 \%)$ & $6(7.3 \%)$ & $=0.057$ \\
\hline & GIIb/IIIa inhibitors & $8(44.4 \%)$ & $2(2.4 \%)$ & $<0.0001 * *$ \\
\hline
\end{tabular}

* Percentage of Column Total.

Comparative study between the 2 groups revealed; highly significant increase in GIIb/IIIa inhibitors usage, in MACE group; compared to normal group; with highly significant statistical difference $(\mathrm{p}<$ $0.051)$.

Correlation studies regarding follow up (outcome) data:

Correlation studies between different MACE outcomes; and its relative independent predictors (baseline clinical, laboratory, echocardiographic, coronary, and interventional variables) will be conducted with multiple, logistic regression analysis and Spearman's correlation coefficient (as suitable).
Comparative study between the 2 groups revealed non- significant difference as regards number of treated coronaries, total stented length, Baseline PCI, and CABG interventions ( $p>0.05)$.

\#\# List of predictor variables (included in the regression model):

1. Age

2. Sex

3. Baseline clinical data

4. Baseline laboratory data

5. Baseline echocardiographic data 6Coronary affection data

6. Syntax score

7. Baseline clinical data

8. Interventional data (Baseline and current)

Table (8): Logistic regression model for the Factors affecting MACE occurrence using Forward method:

\begin{tabular}{l|l|l|l} 
Predictor Factor & Coefficient & $\begin{array}{l}\text { Std. } \\
\text { Error }\end{array}$ & P value \\
(Constant) & 27.33371 & & \\
\hline Age & 5.15145 & 1.81493 & $0.0045^{* *}$ \\
\hline Positive Family History & 5.67390 & 2.35213 & $0.015^{*}$ \\
\hline EF & -0.49679 & 0.15401 & $0.0013^{* *}$ \\
\hline Syntax score & 2.76524 & 0.96541 & $0.0011^{* *}$ \\
\hline GIIb/IIIa inhibitors & 11.48113 & 3.79065 & $0.0025^{* *}$
\end{tabular}

-- excluded from the model if ( $\mathrm{p}$ value $>0.1$ ).

Logistic regression analysis shows that; after applying (Forward method) and entering some predictor variables; the increase in age, positive FH, GIIb/IIIa inhibitors usage, increase in syntax score and the decrease in baseline EF; had an independent effect on increasing the probability of MACE occurrence; with significant statistical difference $(\mathrm{p}<0.05$ respectively). 


\section{DISCUSSION}

This was a prospective observational study conducted on 100 patients, to assess the mid and short-term clinical outcomes in diabetic patients (DM) with stable coronary artery disease (CAD), treated with $2^{\text {nd }}$ generation Drug Eluting Stents (DES).

A total of 100 DM-CAD patients, recruited from the department of cardiology, Tanta University Hospitals. The duration of the study was one year. Hundred patients included in this study.

Patients were subjected to full medical history, general and cardiac examinations, investigations, ECG, and standard transthoracic Echocardiography (TTE). Follow up data will be obtained according to MACE (major adverse cardiac events) criteria including: death, myocardial infarction (STEMI and NSTEMI), cerebrovascular stroke, in-stent restenosis, stent thrombosis, and target lesion revascularization.

Regarding baseline data, we found that; the mean age of all patients was $(57.96 \pm 8.32)$ years, a result which came in agreement with Park et al. ${ }^{(7)}$.

Park et al. ${ }^{(7)}$ conducted a large, prospective, randomized, multicenter OPTIMIZE trial, and reported an average age of DM group of patients of 62.1 years.

Regarding gender of the patients, the majority (64\%) of patients were males; while $(36 \%)$ were females, with $(36 \%)$ of patients had positive family history, a results which came in agreement with Daemen and his colleagues in 2007, who reported that, most patients were males representing about (75\%), and (28\%) had positive family history for cardiovascular disease ${ }^{(3)}$.

We found that; the mean BMI of all patients was $(30.7 \pm 4.6)$. Regarding risk factors and comorbidities, $(58 \%)$ of patients were smokers, and $(64 \%)$ had HTN, a results which came in agreement with Martini and Kent ${ }^{(8)}$, who reported that, several risk factors have been identified that contribute to the progression of this disease and include smoking, hypertension, and diabetes.

We also found that; the mean creatinine of all patients was $(1.06 \pm 0.24) \mathrm{mg} / \mathrm{dl}$. Regarding ECG abnormalities, $(90 \%)$ of patients had abnormal ECG findings, with (64\%) had inverted $\mathrm{T}$ wave, $(10 \%)$ had ST depression, $(6 \%)$ had pathological Q, and (22\%) had LBBB.

We also found that; the mean EF of all patients was $(60.5 \pm 10.7 \%)$; with $(72 \%)$ of patients had RWMA, (54\%) of patients had LVH. Regarding grades of DD, (84\%) of patients had grade I DD, and $(16 \%)$ had grade II DD.

Regarding valve abnormalities, (9\%) of patients had mild MR, and (8\%) had mild TR.

We also found that; the average number of affected coronaries was $(1.6 \pm 0.7)$; with LAD affected in $(68 \%)$ of patients, LCX in $(34 \%)$, and RCA in (58\%), a result which came higher than that of Kedhi et al. ${ }^{(9)}$.

Kedhi et al. ${ }^{(9)}$ studied 3,928 patients received $2^{\text {nd }}$ generation DES (Everolimus), and reported LAD affection in $42.8 \%$ of DM patients, and $26.2 \%$ RCA affection in the same group of patients.

Regarding interventional data, we found that; $(6 \%)$ of patients had prior PCI, $(10 \%)$ had prior CABG, and (10\%) used GIIb/IIIa inhibitors, a results which came lower than that of Faggioni et al. ${ }^{(10)}$, who reported that (44\%) and (17.1\%) of DM patients had prior PCI and CABG respectively.

We also found that; the average number of treated coronaries was $(1.3 \pm 0.5)$; while the average total stented length was $(48.6 \pm 26.2)(\mathrm{mm})$.

Regarding mid and short-term follow up or outcome data, we found that; the prevalence of MACE events was (18\%), with mortality rate of (2\%), and (6\%) had NSTEMI, (12\%) had IRS, (2\%) had stent thrombosis, and (6\%) had target lesion revascularization, a results which came in agreement with Nakatsuma et al. ${ }^{(11)}$.

Kedhi et al. ${ }^{\left({ }^{9}\right)}$ reported that, $2^{\text {nd }}$ generation DES (G2-DES) was associated with significantly lower rates of adverse events compared with $1^{\text {st }}$ generation DES (HR: 1.99; 95\% confidence interval [CI]: 1.19 to 3.08$)$.

On the other hand, Nakatsuma et al. (11) mentioned that, G2- DES provided similar risk for TLR in non DM patients compared with G1-DES. However, G2-DES compared with G1-DES had a lower risk for TLR among DM patients.

The 100 DM-CAD patients were further classified according to MACE outcome into 2 independent groups: MACE group (18 patients) and normal group (82 patients).

Regarding baseline data, comparative study between the 2 groups revealed non-significant difference as regards age, sex and family history ( $\mathrm{p}$ $>0.05$ ) a results which came in agreement with Nakatsuma et al. ${ }^{(11)}$.

Comparative study between the 2 groups revealed non- significant difference as regards height, weight, BMI, HTN and smoking ( $p>0.05$ ) a results which came in agreement with Nakatsuma et al. ${ }^{(11)}$.

Comparative study between the 2 groups revealed; significant increase in inverted $\mathrm{T}$ wave in MACE group; compared to normal group; with significant statistical difference $(\mathrm{p}=0.015)$, a results which came in agreement with Kedhi $\boldsymbol{e t}$ al. (9), who reported that, rates of early definite cardiac ischemia were significantly higher for G1-DES drugs as compared with G2-DES Everolimus (PES vs. EES: HR: 3.78, 95\% CI: 1.31 to 10.39; SES vs. 
EES: HR: $4.45,95 \%$ CI: 1.24 to 15.91$)$.

Comparative study between the 2 groups revealed non- significant difference as regards creatinine, ST elevation, ST depression, pathological Q, LBBB and RBBB ( $p>0.05$ ).

Also, there was highly significant decrease in EF in MACE group; compared to normal group; with highly significant statistical difference $(\mathrm{p}<$ 0.01).

Also, there was non-significant difference as regards RWMA, LVH, and grades of DD ( $p>0.05)$.

Harada et al. (12) reported ECG and echocardiographic results, similar to our study except for $\mathrm{EF}$, which was non-significantly different.

Comparative study between the 2 groups also revealed; highly significant decrease in number of affected coronaries, especially RCA affection, in MACE group; compared to normal group; with highly significant statistical difference $(\mathrm{p}<0.05$ respectively). Also, there were non-significant difference as regards LM, LAD, and LCX affection ( $\mathrm{p}>0.05)$.

Nakatsuma et al. ${ }^{(11)}$ results came close to our study regarding number of affected coronaries and LAD and LCX affection, but not in LM affection.

Regarding interventional data, comparative study between the 2 groups revealed; highly significant increase in GIIb/IIIa inhibitors usage, in MACE group; compared to normal group; with highly significant statistical difference $(\mathrm{p}<0.051)$.

Comparative study between the 2 groups revealed non- significant difference as regards number of treated coronaries, total stented length, prior PCI, and CABG interventions ( $p>0.05)$, a results which came in agreement with Nakatsuma et al. ${ }^{(11)}$.

On the other hand, Faggioni et al. ${ }^{(\mathbf{1 0})}$ disagreed with results and reported that, the use of glycoprotein IIb/IIIa inhibitors was similar between the 2 groups.

Also, Faggioni et al. ${ }^{(10)}$ reported that, diabetic status was associated with a history of cardiovascular diseases, including previous MI, previous PCI with stent implantation, coronary artery bypass graft surgery, stroke, and peripheral vessel disease.

Correlation studies between different MACE outcomes; and its relative independent predictors (baseline clinical, laboratory, echocardiographic, coronary, and interventional variables) revealed the following results.

Logistic regression analysis shows that; after applying (Forward method) and entering some predictor variables; the increase in positive family history, syntax score, GIIb/IIIa inhibitors usage; and the decrease in baseline EF; had an independent effect on increasing the probability of MACE occurrence; with significant statistical difference ( $\mathrm{p}$ $<0.05$ respectively). Our results came in agreement with Urban et al. ${ }^{(13)}$.

Bavishi et al. ${ }^{(14)}$ on his large meta-analysis of eighteen randomized controlled trials comprising of 8095 patients (17,000 patient-years of follow-up) were included. Compared to first- generation DES, G2-DES significantly decreased MACE by $18 \%$ (relative risk [RR]: $0.82,95 \%$ confidence interval [CI]: $0.70-0.96)$, myocardial infarction by $43 \%$ (RR: $0.57,95 \%$ CI: $0.39-0.84$ ) and stent thrombosis by $46 \%$ (RR: $0.54,95 \%$ CI: $0.35-0.82$ ) in patients with diabetes. Moreover G2-DES showed a trend towards reduction in rates of TLR and TVR $(\mathrm{p}=0.05)$. ZES was associated with $89 \%$ increased risk for TLR (RR: 1.89 , 95\% CI: 1.10-3.22) compared to first- generation DES. Furthermore, meta-regression analysis showed a greater magnitude of benefit of G2-DES over firstgeneration DES for MACE $(p=0.037)$ and stent thrombosis $(p=0.036)$ in diabetic patients requiring Insulin ${ }^{(14)}$.

\section{CONCLUSION}

It could be concluded that diabetes mellitus is a condition in which the use of 2 nd generation zotarolimus-eluting stents is preferable, in order to reduce the incidence of MACE adverse events.

\section{RECOMMENDATIONS}

- The expanded use of 2 nd generation drugeluting stents is preferable especially in DM patients.

- Proper control of DM leads to enhancement of DES efficacy, and decrease the incidence of MACE events.

\section{REFERENCES}

1. Bangalore S, Kumar S, Fusaro M et al. (2012): Outcomes with various drug eluting or bare metal stents in patients with diabetes mellitus: mixed treatment comparison analysis of 22,844 patient years of followup from randomised trials. BMJ., 345:e5170.

2. Cutlip DE, Chhabra AG, Baim DS et al. (2004): Beyond restenosis: Five-year clinical outcomes from second-generation coronary stent trials. Circulation, 110: 1226-1230.

3. Daemen J, Wenaweser P, Tsuchida K et al. (2007): Early and late coronary stent thrombosis of sirolimuseluting and paclitaxel-eluting stents in routine clinical practice: Data from a large two-institutional cohort study. Lancet, 369: 667-678.

4. Finn AV, Nakazawa G, Joner M et al. (2007): Vascular responses to drug eluting stents: importance of delayed healing. Arterioscler Thromb Vasc Biol., 27:1500-1510. 
5. Joner M, Finn AV, Farb A et al. (2006): Pathology of drug-eluting stents in humans: delayed healing and late thrombotic risk. J Am Coll Cardiol., 48:193-198.

6. Mazzone T, Chait A, Plutzky J (2008): Cardiovascular disease risk in type 2 diabetes mellitus: insights from mechanistic studies. Lancet, 371:18001809.

7. Park KW, Lee JM, Kang SH et al. (2014): Everolimus-eluting Xience v/Promus versus zotarolimus-eluting resolute stents in patients with diabetes mellitus. JACC Cardiovasc Interv., 7:471-481.

8. Martini S, Kent T (2007): Hyperglycemia in acute ischemic stroke: a vascular perspective. J Cereb Blood Flow Metab., 27:435-39.

9. Kedhi E, Gomes ME, Lagerqvist B et al. (2012): Clinical impact of second-generation everolimuseluting stent compared with first-generation drugeluting stents in diabetes mellitus patients: insights from a nationwide coronary intervention register. JACC Cardiovasc Interv., 11:1141-9.

10. Faggioni M, Baber U, Sartori S et al. (2017): Incidence, Patterns, and Associations Between DualAntiplatelet Therapy Cessation and Risk for Adverse Events Among Patients With and Without Diabetes Mellitus Receiving Drug-ElutingStents: Results From the PARIS Registry. JACC Cardiovasc Interv., 10(7):645-654.

11. Nakatsuma $K$, Shiomi $H$, Morimoto $T$ et al. (2018): CREDO-Kyoto PCI/CABG Registry Cohort-2 Investigators. Influence of a history of cancer on longterm cardiovascular outcomes after coronary stent implantation (an Observation from Coronary Revascularization Demonstrating Outcome StudyKyoto Registry Cohort-2). Eur Heart J Qual Care Clin Outcomes, 4(3):200-207.

12. Harada T, Wilbraham D, de La Borderie G et al. (2014): Cardiac Effects of Amiselimod Compared with Fingolimod and Placebo: Results of a Randomised, Parallel-group, Phase I Study in Healthy Subjects. Clinical Trials, 12: 1-26.

13. Urban P, Meredith IT, Abizaid A et al. (2015): Polymer-free drug-coated coronary stents in patients at high bleeding risk. N Engl J Med., 373:2038-2047.

Bavishi C, Baber U, Panwar S et al. (2012): Efficacy and safety of everolimus and zotarolimuseluting stents versus first-generation drug-eluting stents in patients with diabetes: A metaanalysis of randomized trials. Int J Cardiol., 230:310318. 